University of Nebraska - Lincoln

DigitalCommons@University of Nebraska - Lincoln

Faculty Publications, UNL Libraries

Libraries at University of Nebraska-Lincoln

$1-28-1989$

\title{
Silica Exposure and Silicosis Among Ontario Hardrock Miners: I. Methodology
}

D. C. F. Muir

Occupational Health Program, McMaster University, Hamilton, Ontario, Canada

H. S. Shannon

Occupational Health Program, McMaster University, Hamilton, Ontario, Canada, shannonh@mcmaster.ca

J. A. Julian

Occupational Health Program, McMaster University, Hamilton, Ontario, Canada

D. K. Verma

Occupational Health Program, McMaster University, Hamilton, Ontario, Canada, vermadk@mcmaster.ca

A. Sebestyen

Occupational Health Program, McMaster University, Hamilton, Ontario, Canada

See next page for additional authors

Follow this and additional works at: https://digitalcommons.unl.edu/libraryscience

Part of the Library and Information Science Commons

Muir, D. C. F.; Shannon, H. S.; Julian, J. A.; Verma, D. K.; Sebestyen, A.; and Bernholz, Charles D., "Silica Exposure and Silicosis Among Ontario Hardrock Miners: I. Methodology" (1989). Faculty Publications, UNL Libraries. 101.

https://digitalcommons.unl.edu/libraryscience/101

This Article is brought to you for free and open access by the Libraries at University of Nebraska-Lincoln at DigitalCommons@University of Nebraska - Lincoln. It has been accepted for inclusion in Faculty Publications, UNL Libraries by an authorized administrator of DigitalCommons@University of Nebraska - Lincoln. 


\section{Authors}

D. C. F. Muir, H. S. Shannon, J. A. Julian, D. K. Verma, A. Sebestyen, and Charles D. Bernholz 


\title{
Silica Exposure and Silicosis Among Ontario Hardrock Miners: I. Methodology
}

\author{
D. C. F. Muir, PhD, FRCP; H. S. Shannon, PhD; J. A. Julian, MMath; \\ D. K. Verma, PhD, CIH; A. Sebestyen, BSC; C. D. Bernholz, MA
}

Occupational Health Program, McMaster University, Hamilton, Ontario, Canada

Accepted for publication December 12, 1988.

\begin{abstract}
An epidemiological investigation was undertaken to determine the relationship between silicosis in hardrock miners in Ontario and cumulative exposure to silica (crystalline silica $-\alpha$ quartz) dust. This first report describes the cohort, the method of classifying the radiographs, and the identification of a case of silicosis.
\end{abstract}

Key words: pneumoconiosis, silica, quartz, respirable dust, konimeter, dose-response relationship

\section{INTRODUCTION}

The objective of this investigation has been to examine the relationship between exposure to airborne dust and the development of silicosis in Ontario hardrock miners. Such information is valuable for estimating the risks of silicosis associated with different concentrations of dust and can provide guidance concerning control levels in the mining industry.

The overall approach of the research was to obtain estimates of cumulative dust exposure for each miner and to relate this to the radiological category of pneumoconiosis. The project was overseen by a joint committee with representation from the industry, the unions, the Workers' Compensation Board, and the Ministry of Labour of the Government of Ontario.

The justification for the study is a result of the relative paucity of reliable data about exposure-response relationships in silicosis despite its preeminence as one of the diseases earliest recognized to be of occupational origin. Silicosis was probably the lung disease caused by dusty air at work referred to by Agricola in 1556 [Agricola, 1950]. The opportunity to undertake an epidemiological study was provided by the information collected in the mining industry of Ontario during the last 50 years. These data are derived from three principal sources:

1. Full-sized chest radiographs were taken annually on all miners after 1927. These films were obtained from the Ministry of Labour chest clinics in the Ontario mining districts, and from the Government of Ontario archives.

2. Dust measurements obtained by using konimeters were carried out in the mines, and many of these records have been preserved. Before 1959, konimeter mea- 
surements were obtained only when the Mines Accident Prevention Association of Ontario (MAPAO) was asked to conduct a mine dust survey or by mine personnel when a dust control problem was perceived. After 1959, mine dust concentrations, as measured by the mine ventilation engineers, were reported routinely, on a semiannual basis, to the MAPAO.

3. Employment records specifying mine, job, and start dates were available from the Workers' (previously Workmen's) Compensation Board (WCB) master file of miners. The file consisted of miners who had attended the WCB clinics for medical examinations and chest radiography, who were then employed in Ontario, and who fulfilled the following criteria: a) 60 months or more of employment in jobs classified as "dusty" (surface or underground, in Ontario or elsewhere); b) any miner with an xray classified as 4-9 on the Ontario scale (approximately equal to $0 / 1$ or greater on the ILO scale); c) any uranium miner with more than 2 weeks of exposure.

The master file contains the names of many thousands of miners since the clinics were established in 1927 and is continually updated. The difference in inclusion criteria for the WCB master file is related to the minimum period of exposure which was felt to be important in the development of silicosis, when the file was first established. More recently, attention in the uranium mines was focused on lung cancer, and miners with more than 2 weeks of exposure were included.

\section{DEFINITION OF THE COHORT}

The basic source of information was the WCB master file. Since dust measurements from the early years were sparse, only miners starting work after 1940 were selected. To ensure an adequate duration of observation, no miners starting after 1959 were included. Finally, it became evident that dust exposure information was available only in the larger gold and uranium mines possessing adequate record facilities. Twenty-one mines were found to possess adequate records and formed the focus of the study. Dust exposure data were not available prior to 1959 for the nickel/copper mines and these mines were excluded even though they employed large numbers of men. Miners in the cohort were followed up to the end of dust exposure or until December 31, 1982, whichever came first. The final cohort consisted of 2,109 miners first exposed in mining between 1940 and 1959 who spent $80 \%$ or more of their total mining experience in the designated mines.

The ages of the 2,109 men in the cohort and the duration of follow-up are shown in Table I.

\section{MORBIDITY ASCERTAINMENT Radiological Classification-The Diagnosis of Silicosis}

All films of the 2,109 men were assembled and classified by five readers. Preliminary examination showed that the films were of very variable quality. In such circumstances great inter- and intrareader variability can be anticipated [Fletcher and Oldham 1949; Liddell, 1961; Wise and Oldham, 1963; Pearson et al., 1965; Reger and Morgan, 1970; Reger et al., 19721, and this can make interpretation of the results extremely difficult. For this reason the following strategy was developed to ensure that no case of early silicosis was missed and that the diagnosis was as accurate as possible: 


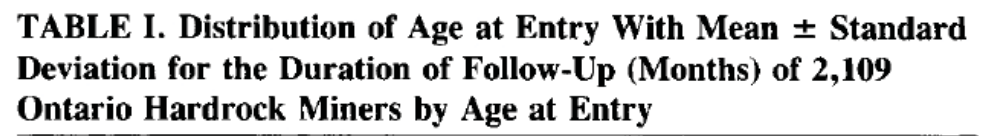

\begin{tabular}{lcc}
\hline $\begin{array}{l}\text { Age at entry } \\
\text { (years) }\end{array}$ & N & $\begin{array}{c}\text { Mean } \pm \text { standard deviation of } \\
\text { duration of follow-up (months) }\end{array}$ \\
\hline$\leq 20$ & 439 & $219 \pm 128$ \\
$20-24$ & 580 & $213 \pm 127$ \\
$25-29$ & 486 & $224 \pm 130$ \\
$30-34$ & 299 & $222 \pm 115$ \\
$35-39$ & 202 & $201 \pm 101$ \\
$\geq 40$ & 103 & $191 \pm 83$ \\
\hline
\end{tabular}

Step I. The two most recent films of each miner were examined independently by four readers. If there was any doubt by any reader that a film was completely normal then all films of that miner were selected for further evaluation. It was assumed that if the two most recent films did not show evidence of silicosis then all preceding films must also have been free of silicosis. On clinical grounds this appears to be a reasonable assumption. (The films of 62 men were available only on microfilm. The last two films of these men were read by only one reader [D.C.F.M.] and all were assessed as normal.)

Step II. Based on this initial screening, the films of 650 miners required further scrutiny. In order to obtain information about the development of silicosis a novel approach was used. Each of five readers separately classified all six zones of the lung fields according to the prevalence and type of opacity by using the ILO [1980] standard reference films. The films were presented in random order, mixing the films from different miners. When two or more readers classified any one of the zones as $1 / 1$ or greater for small opacities, all films of that miner were selected for further evaluation. The films of 48 miners were selected for the final step.

Of the 48 miners whose films were selected for final scrutiny, 32 were considered by one or more of the readers to have silicosis as defined above. In general, the ILO [1980] system of reference films is validated for epidemiological purposes on groups of workers. Although the approach used in this paper is much closer to an individual clinical method, the results are interpreted in an epidemiological sense.

Step III. All films of these 48 miners were presented to each reader. The readers were asked to categorize the films in the normal manner according to the ILO [1980] standard reference films for small round opacities but with one restriction. By taking account of information provided by the opportunity to view all films in known sequence from a single miner displayed on a series of viewing boxes at the same time, the reader was required to ensure a progression of radiological abnormality if present.

The purpose of this maneuver was to enable as accurate a diagnostic evaluation of each miner as possible. Silicosis is a disease which is not thought to improve or regress. However, the presence of poor-quality films in a series may result in a situation in which regression appears to occur if the films are presented in an independent randomized fashion. Equally, it follows that a good-quality normal film in a series cannot be preceded by films showing true evidence of silicosis. 
The increased ease of reading all films of each miner in a single session was noteworthy. This effect was presumably an extension of the decreased variability noted when pairs of films are read side by side [Amandus et al., 19731. A comparison of the intra- and interreader variability in the different methods and the natural history of the development of silicosis will be presented in a further report.

For the purposes of the analyses, it was considered that silicosis is characterized by the presence of small, round opacities. Irregular opacities may result either from occupational dust exposure or from other contaminants such as cigarette smoke, and their significance will be evaluated at a later stage. The silicotic nodule is classically a lesion with relatively little dust content but with surrounding collagen such that it is visible as a round opacity on a radiograph [Parkes, 1982]. Some readers considered round opacities at the apex of the lungs in certain films to be possibly the result of tuberculosis rather than of silicosis. Three readers were asked to identify such a clinical diagnosis in each case. However, there appeared to be little agreement between the readers, and it was decided to include all films showing small, round opacities in the analysis so that the effects of dust exposure would not be underestimated. It was therefore determined that a positive diagnosis of silicosis was established by each reader if the radiological category for small, round opacities (whether or not combined with irregular opacities) was $1 / 1$ or greater. This definition does not assume that films in all lower categories are normal. However, for risk estimation, the choice of end point is arbitrary. A 1/1 categorization indicates that the film was definitely assessed as abnormal and was not seriously considered by the reader to be normal [Liddell, 1963]. On the other hand, this represents an early stage of disease which is not associated with physiological abnormality [Irwig and Rocks, 19781 and may present an appropriate point at which to advise against further exposure for that miner.

Because of the well-recognized differences in classification levels between readers, the numbers of silicotic cases identified by each reader were not identical. Moreover, even in cases where all readers agreed that silicosis developed eventually, there was no unanimity concerning the first film at which the $1 / 1$ category was reached. In the present study, no attempt was made to "average" the five readings of each film. Instead, the analyses of exposure/response were determined for each reader separately.

\section{DUST EXPOSURE ASCERTAINMENT}

For each miner in the cohort a record of cumulative exposure to respirable silica was prepared. This was accomplished by compiling a detailed work history and by associating this with estimates of dust exposure. Since the airborne dust measurements had been obtained by means of a konimeter, an extensive side-by-side comparison of the konimeter and gravimetric sampling was undertaken. This was necessary in order to convert the konimeter data to equivalent gravimetric silica estimates. The undertaking constituted a major part of the whole investigation and is described in part II [Verma et al., 1989] of this series.

\section{DISCUSSION}

The cohort selected for this study does not constitute a reliable base for estimating the burden of silicosis affecting miners starting work in Ontario between 1940 and 
1959 nor of the dust conditions to which they were exposed. Those working in small mines were excluded, and it may be that environmental conditions in such mines were different from those in the larger ones. However, this exclusion does not provide a source of bias affecting the overall relationship between silicosis and dust exposure. The inclusion of miners working in the nickel/copper mines would have been desirable. This is because the fractional content of silica in the respirable dust in these mines is significantly lower than in the gold or uranium mines. There is evidence (in the coal-mining industry) that the fractional concentration of silica in the airborne dust is a factor governing the probability of developing pneumoconiosis in addition to the absolute silica concentration [Walton et al., 1977]. However, as noted above, exposure records had not been preserved in these mines.

In the study, the radiographs of miners in the cohort were examined to detect the onset of silicosis. Routine radiographs were generally taken only as long as the miner worked in Ontario; therefore, to be included as a case in the study, the miner had to develop silicosis while employed at a mine in Ontario. It is evident that this could bias the results in that silicosis might have appeared after the miner had left the industry even in the absence of further dust exposure. A radiological survey of retired miners would be necessary to determine this. This is an important point because many of the miners had inhaled finely divided aluminum dust prior to underground work, since this was thought to be a prophylactic measure. The practice was subsequently abandoned in view of the lack of evidence of benefit in human populations and its obvious ethical issues. There are strong reasons for suggesting a follow-up investigation, despite the administrative difficulties. We need to know whether cessation of aluminum therapy could have led to the unmasking of silicotic lesions after the miners left the industry.

It is possible that some miners whose radiography showed the very earliest abnormalities due to dust exposure might, on medical advice, have chosen to leave the industry. This was given in privacy by a number of physicians, and it is no longer possible to identify the reasons why individual miners sought alternative work.

In some instances there was a gap or missing film in the series. For example, a given radiograph might be read as $1 / 0$ and the next available film taken some time later be rated $1 / 2$. In these circumstances it was not possible to identify the exact date at which a miner's radiograph might have reached the $1 / 1$ boundary point. The date of the $\mathrm{x}$-ray first rated $1 / 1$ or worse was chosen as the reference point. In general, of course, this will be later than the "true" date at which the disease developed. This, in turn, will lead to a slight overestimate of the dust level required to produce disease at the $1 / 1 \mathrm{lev}-$ el (and conversely an underestimate of the risks of various levels of exposure).

The purpose of the radiological protocol described above was to develop an efficient system for the accurate identification of category $1 / 1$ silicosis in a small number of subjects from within a large pool of films. A total of about 17,000 radiographs was available, and the possibility of independent randomized assessment of each film by each of the five readers was rejected after an initial examination demonstrated wide variations of film quality. The radiographs had been taken by many different radiographers and had been in storage for up to 40 years. Although the identification of advanced silicosis presents little difficulty, it is less easy to distinguish early changes from artifacts caused by poor radiographic technique or by the presence of tuberculosis which was fairly prevalent in the early years of the industry. 
As may be expected, there was disagreement between observers as to whether opacities in some instances should be classified as round or irregular. Even when all observers agreed on the type of opacity, there was no overall agreement on the category. The task of reading was greatly facilitated by the method of viewing all films from a single miner displayed at the same time. The additional confidence and ease of categorizing a single film in a given category was noted by all readers and the method appears to have real advantages.

Various approaches have been used to deal with the problem of variability between readers. These include averaging techniques or consensus reading. In the present study, each reader was required to identify pneumoconiosis (if present) and the $1 / 1$ level (if reached). In these circumstances exposure/response estimates, and subsequently, pooled risk estimates, were obtained for each reader separately. Risk estimates for consensus reading, from one to all reader agreement, were also determined. The methodology is described in report III of this series [Muir et al., 1989].

The characterization of silicosis by the presence of round opacities, whether or not associated with irregular opacities, is consistent with the pathological description of the silicotic nodules [Parkes, 1982]. The miners in the study were exposed to other pollutants including cigarette smoke, diesel fumes, and a wide range of silicotic rock compounds. The relationship of the irregular opacities to dust exposure will be investigated in a subsequent report.

\section{SUMMARY}

The methodology of an epidemiological investigation of the relationship between cumulative exposure to airborne silica and the probability of developing silicosis is described. Full-sized chest radiographs were categorized on the ILO [1980] scale by five readers working independently. The films were first screened to identify a group of miners including all those with possible silicosis, whose films were then subjected to more detailed scrutiny. All films from these miners were read in a single series with all films from a single miner visible at the same time. Pneumoconiosis was identified as the presence of small, round opacities of profusion $1 / 1$ or greater.

\section{ACKNOWLEDGMENTS}

The investigation was funded by the Ontario Mining Association, the Ministry of Labour of the Government of Ontario, and the Workers' Compensation Board of Ontario. Our thanks are due to these agencies and for the support of the members of the steering committee.

Special acknowledgment is made to miners who participated in the investigations, to mine management, and to representatives of the United Steel Workers of America and the Union of Mine Mill and Smelter Workers at the mines where the investigations took place. A large number of chest radiographs were classified by Drs. J. Chan, J. Roos, W. Maehle, and W.K.C. Morgan, to whom we express our great thanks. 


\section{REFERENCES}

Agricola G (1950): "De re metallica” (Translated by Hoover HC and Hoover LH). New York: Dover.

Amandus HE, Reger RB, Pendergrass EP, Dennis JM, Morgan WKC (1973): The pneumoconioses: Methods of measuring progression. Chest 63:736-743.

Fletcher CM, Oldham PD (1949): The problem of consistent radiological diagnosis in coalworkers' pneumoconiosis: an experimental study. Br J Ind Med 6:168-183.

International Labour Office (1980): "Guidelines for the Use of ILO International Classification of Radiographs of Pneumoconioses. Rev. Ed. 1980. Occupational Safety and Health Series, No. 22 (Rev.80)." Geneva: International Labour Office.

Irwig LM, Rocks P (1978): Lung function and respiratory symptoms in silicotic and non-silicotic gold miners. Am Rev Respir Dis 117:429-435.

Liddell FDK (1961): The effect of film quality on reading radiographs of simple pneumoconiosis in a trial of x-ray sets. Br J Ind Med 18: 165-174.

Liddell FDK (1963): An experiment in film reading. Br J Ind Med 20:300-312.

Muir DCF, Julian JA, Shannon HS, Verma DK, Sebestyen A, Bernholz CD (1989): Silica exposure and silicosis among Ontario hardrock miners: III. Analysis and risk estimates. Am J Ind Med 16:29-43.

Parkes WR (1982): “Occupational Lung Disorders” (2nd ed.). London: Butterworths.

Pearson NG, Ashford JR, Morgan DC, Pasqual RSH, Rae S (1965): Effect of quality of chest radiographs on the categorization of coalworkers' pneumoconiosis. Br J Ind Med 22:8192.

Reger RB, Morgan WKC (1970): On the factors influencing consistency in the radiologic diagnosis of pneumoconiosis. Am Rev Respir Dis 102:905-915.

Reger RB, Smith CA, Kibelstis JA, Morgan WKC (1972): The effect of film quality and other factors on the roentgenographic categorization of coal workers' pneumoconiosis. Am J Roentgenol Rad Ther Nucl Med 115:462-472.

Verma DK, Sebestyen A, Julian JA, Muir DCF, Schmidt H, Bernholz CD, Shannon HS (1989): Silica exposure and silicosis among Ontario hardrock miners: II. Exposure estimates. Am J Ind Med 16:13-28.

Walton WH, Dodgson J, Hadden GG, Jacobsen M (1977): The effect of silica and other noncoal dusts in coalworkers' pneumoconiosis. Part I: Epidemiological studies. In Walton WH, McGovern B (eds): “Inhaled Particles, IV (II).” London: Pergamon Press, pp 669690.

Wise ME, Oldham PD (1963): Effect of radiographic technique on readings of categories of simple pneumoconiosis. Br J Ind Med 20: 145-153. 